\title{
CRYPTOCURRENCY: PROBLEMATIC ASPECTS OF LEGAL REGULATION
}

\begin{abstract}
The article is devoted to the analysis of the legal nature of the cryptocurrency as an object of financial and legal regulation from the point of view of Russian legislation. It includes the analysis of the qualification of the cryptocurrency described as money, electronic money, foreign currency, other property, as well as the possibility of assigning crypto-loans to obligations rights. The conclusion is made about the possibility of treating cryptocurrency as private money on a par with national currencies.
\end{abstract}

Keywords: cryptocurrency, blockchain, financial law

\section{Introduction}

With the introduction of new digital technologies, the emergence and development of new objects, which are based on public blockchain of such cryptocurrency as Bitcoin, Lightcoin, Ethereum, etc. (hereinafter "cryptocurrency"), there is a need for legal regulation of both the very instruments and relations arising in connection with their use in general.

Currently, legal discussions are quite brisk about the legal nature of the cryptocurrency [Ponsford 2015, Prayogo 2018]. The qualification of the cryptocurrency is one of the most important aspects as an object of civil rights, which creates the conditions for legal regulation of transactions with the use of cryptocurrency, which will simultaneously allow legal regulation and settle other equally important issues of relations arising in connection with the use of cryptocurrencies.
Nowadays, most of the countries are trying to analyse the status of cryptocurrency and introduce legal regulation meeting the interests of the state and business.

\section{Cryptocurrency Is Money}

As you know, the notion "money" is an economic substance, thanks to the works of Friedrich A. Hayek, McConnell K.R., Bru S.L., M. Friedman, J.M. Keynes, L. Harris [1975, p. 5, 2003, p. 938, 2016, p.17, 1990, p. 750] and other well-known economists, whose works were devoted to the study of economic relations. Money is a special commodity, which is the universal equivalent of the value of other goods and services. Modern economic science distinguishes five functions of money.

1. Measure of value. Money allows you to evaluate the value of goods by setting prices.

2. Means of circulation. Money plays the role of an intermediary in the process of exchange.

3. Means of payment. The function of money that allows the time of payment not to coincide with the time of payment, that is, when the goods are sold on credit.

4. Means of accumulation and saving. The ability of money to participate in the process of formation, distribution, redistribution of national income, formation of savings of the population.

5. The function of world money. It manifests itself in the relations between economic entities: states, legal entities and individuals, located in different countries.

It is believed that money fulfils its task only under the condition of the participation of people who use the 
opportunities of money. Only people can determine the prices of goods, apply money in the realization and payment processes, and also use them as a means of accumulation. Thus, theoretically, any object that performs these functions can be considered money.

Another important aspect of the notion of "money" is connected with the notion of a "legal tender" and state monopoly on money issue. In accordance with Article 75 of the Constitution of the Russian Federation, the ruble is the monetary unit in the Russian Federation. Monetary emission is carried out exclusively by the Central Bank of the Russian Federation. Introduction and emission of other money in the Russian Federation is not allowed.

According to Article 140 of the Civil Code of the Russian Federation, the ruble is a legal tender, mandatory for acceptance at face value throughout the territory of the Russian Federation.

Payments in the territory of the Russian Federation are made by cash and non-cash payments.

Cases, procedure and conditions for the use of foreign currency in the territory of the Russian Federation are determined by law or in accordance with the procedure established by it.

As L.A. Luntz noted [2004, p. 35], the legal significance of the legal payment force assigned to a monetary sign is that the creditor under the obligation which can be repaid by way of a monetary payment, having refused to accept the legal tender, falls into delay. The status of legal means of payment allows to repay by proper execution of any monetary obligation in the territory of the Russian Federation by law without the need to express the will of the creditor. All other forms of payment (counter-payments) do not have the status of legal tender. At the same time, a legal means of payment is used to fulfil public-legal obligations of a monetary nature, for example, for paying taxes [Savalyev 2017, p. 24].

Art. 128 of the Civil Code of the Russian Federation attributes to the objects of civil rights things, including cash and certificated securities, other property, including non-cash funds, uncertificated securities, property rights; results of works and services; protected results of intellectual activity and equated to them means of individualization (intellectual property); intangible goods.

In the current Russian legislation, nothing prevents the cryptocurrency from being attributed to civil rights objects, since Article 128 of the Civil Code of the Russian Federation does not contain an exhaustive list, but taking into account that the cryptocurrency performs different functions when it is applied (goods, investments, financial assets ensuring payment of a commission for the implementation of transactions on blockchain technologies, as an essential element of the system, if we consider by analogy as electric power for any production), appropriate are different legal regulation of the cryptocurrency, depending on what function such a cryptocurrency will perform.

\section{Cryptocurrency Is the Equivalent of Cash}

On the example of the most famous cryptocurrency, bitcoin, we can argue that this is an electronic, digital equivalent of cash or that institution that will eventually be able to displace cash. The authenticity of cash is verified through viewing watermarks, security thread, microprinting, with the help of special technical means, etc., while in the case of cash there is no register containing operations records (in this connection there are certain restrictions of cash settlements [The Bank of Russia instruction of 07.10.2013 N 3073-U "About implementation of cash payments", registered in the Ministry of Justice of Russia 23.04.2014 $\mathrm{N}$ 32079] and there is a centuries old problem with their counterfeits of both coins and banknotes), in the case of cryptocurrency - bitcoin, the transaction register guarantees their authenticity. For example, Germany's legislation allows the attribution of cryptocurrencies to financial instruments, which are a form of "private money" that can be taxed [ $\$ 24$ of Article 14 of the Federal law "On the national payment system” №161-FZ of 27.06.2011].

In his work "Private money" Friedrich. A. Hayek offered a radically new way to achieve monetary stability - a system based on the competition of parallel private currencies. His idea is simple, such currency should be recognized as an ordinary commodity and accordingly produced in a market way. In his opinion, "only those currencies will remain that will fulfil the functions of money best of all: to serve as a means of payment and preserve their value over time" [Hayek 1975, p. 5]. It seems that we are on the verge of this reality because of the following.

The society had a need to create an entity similar to cash only in the conditions of a new space. For example, if the simple transfer of a note by one person to another when calculating cash is indicative of the transfer of the value determined by its value, and such a transfer does not require any assurance by the third party, since these are only two persons' relations and nobody prevents them from doing this transfer, then when translating electronic 
funds in order to carry out the transfer of value expressed in electronic money from one person to another there is a necessity to seek help from a third party (bank, nonbank credit institution which on legal grounds acting as an intermediary in relation to these two persons carrying out transfers of electronic money, has the right under certain conditions to question the legality of such transfer and to refuse to carry out the transfer of funds [ $\$ 24$ of Article 14 of the Federal law "On the national payment system” №161-FZ of 27.06.2011].

This example demonstrates that cash can be transferred without any consent of the third party. This factor indicates the unshakable control of such a transfer. And this factor is fundamental for the development of the cryptocurrency, because it is also based on the mechanism of inadmissibility of interference by the third party - control on the one hand, anonymity and reality (genuineness) of the very essence of the cryptocurrency on the other.

Another factor of popularity of the cryptocurrency is its decentralization, unsettled activities of persons, issuing cryptocurrency. In fact, everyone can issue their own cryptocurrency. There is only a question of its market competitiveness, the ability of the circulation and trust of the community, the issue of an agreement on the one hand, but of course the danger, insecurity on the other, which needs legal regulation, and relations of such kind in defence on legislative level.

Thus, if the cryptocurrency is recognized as money, in the sense of the legislation of the Russian Federation, and treated as an alternative monetary unit, then explicit prohibition is clearly seen in relation to such an approach. Accordingly, payment of goods and services with the help of bitcoins and other cryptocurrencies in the territory of the Russian Federation is contrary to the current legislation.

\section{Cryptocurrency Is a Foreign Currency}

The opinion that it is possible to equal the cryptocurrency to foreign currency, have been repeatedly expressed by the media. According to subparagraph 2) of Article 1 of the Federal Law No. 173-FZ of December 10, 2003 (as amended on July 18, 2017) "On Currency Regulation and Currency Control" [Paragraph 24 of article 14 of the Federal law "On the national payment system” №161-FZ of 27.06.2011] (hereinafter the "Law on Currency Regulation"), the foreign currency is:
- token money in the form of banknotes, treasury notes, coins in circulation and being a legal means of cash payment in the territory of the relevant foreign state (group of foreign states), as well as have been withdrawn or are withdrawn from circulation, but subject to exchange the indicated banknotes;

- funds in bank accounts and in bank deposits in monetary units of foreign states and international monetary or settlement units.

From the above definition results that the nature of the cryptocurrency is not covered by the term "foreign currency" because of the following:

1. The cryptocurrency is not materialized in form and does not exist in cash. It is also not covered by the second qualifying attribute, constituting "the recognition of the cash payment as the legal means". For the same simple reason, the absence of a cash form, if one abstracts from the concept of "cash" and considers from the point of view "means of payment", it is also seen that cryptocurrency cannot be attributed to the concept of "foreign currency", because the territory of the Russian Federation is OK (MK (ISO 4217) 003-97) 014-2000.

2. All-Russian Classifier of Currencies (app. by the Resolution of the State Standard of Russia No. 405st of 25.12.2000) (ed. from 02.06.2016), according to which the name of the country and territories correspond to the currency of circulation, and, respectively, there is no such in the indicated classifier, there is no connection between the provisions on cryptocurrency and the correlation of the latter to any country.

3. If viewed through the prism of non-cash foreign currency, according to the regime of existence, cryptocurrency is not accumulated in different bank accounts and deposits and is not covered by the notion (concept) of international monetary and settlement units ${ }^{1}$, since full decentralization is established in respect of the cryptocurrency (the absence of an external or internal administrator in the network guaranteeing (conforming) the correctness of system operations, including the lack of ability to influence the transactions of system participants. The reliability of transactions is

\footnotetext{
1 International settlement unit, international counting currency artificial supranational currency, which was designed to measure international claims and liabilities of payments between countries. It is a form of world money.
} 
ensured in the network by Blockchain technology (replicated distributed database - distributed registry technology), respectively, the equalization of the cryptocurrency to foreign currency from the point of view of the legal regime established by the legislation with respect to foreign currency (by regulations on currency regulation and currency control) is legally incorrect.

\section{Cryptocurrency Is Electronic Money}

In accordance with subparagraph 18) of Article 3 of the Federal Law No. 161-FZ of June 27, 2011 (as add. on July $18,2017)$ "On the National Payment System"(hereinafter referred to as the "Payment System Act"), 'electronic funds' are cash which was previously provided by one person (the person who provided money) to another person who takes into account information on the amount of money provided without opening a bank account (to an obligated person), for the fulfilment of the monetary obligations of the person who had provided money, to the third parties and in respect of which the persons and for which the person who provided the money, has the right to transfer the orders exclusively with the use of electronic means of payment.

Electronic means of payment is a means and (or) a method that allows the client of the operator on money transfer to draw up, certify and transfer orders for the purpose of transferring funds within the framework of the applied forms of non-cash payments with the use of information and communication technologies, electronic media, including payment cards, as well as other technical devices ((item 19) of Article 3 of the Federal Law "On the National Payment System") [Federal law of 27.06.2011 N 161-FZ (ed. of 18.07.2017) "On the national payment system"].

Electronic funds are the right of the owner of electronic money to the operator of electronic funds about their repayment (exchange for cash or non-cash money). Electronic funds are accounted for in a special virtual account ("electronic purse"), while funds are reflected in the bank account of the operator of electronic money due to which (funds) all electronic funds, accounted by the operator of electronic funds, will be paid off. One more detail - before the transfer of electronic funds, it is supposed to be prepaid in cash or non-cash money. After that, it becomes possible to make a payment - the operator of electronic money transfers it to the recipient.
The transfer can be carried out both on the basis of the order of the payer, and on the basis of the demand of the recipient of funds. Electronic money is written off from the virtual account of the payer and included into the recipient's virtual account. After the calculations, electronic money can be transferred back to cash or non-cash form. Electronic money is a means for settlements, the availability of which is possible if there is money in the sense of Article 140 of the Civil Code of the Russian Federation.

Cryptocurrency is not subject to the notion of electronic funds, since it has a different mechanism of origin. The emission of the cryptocurrency is carried out through the decentralized emission. The intermediaries (any special subjects, banks, clearing centres, etc.) do not need to transfer it from one entity to another; there are no territorial borders for translation; it is not possible to cancel a transaction and there is a possibility of converting a fiat currency ${ }^{2}$.

I suppose that the disclosure of the concept of "cryptocurrency" through the notion of "digital financial asset" is not entirely good, because there is some misunderstanding in the difference between such concepts as cryptocurrency and digital assets. Although you can certainly argue that each cryptocurrency is a digital asset in its essence. But they differ in the way they are managed. There are many differences between financial instruments. A digital asset exists in binary format, i.e. binary files are opposed to text files, while text files are a special case of binary files, so in the broadest sense of the word, any file is suitable for the definition of "a binary file".

A digital asset can be placed anywhere - from movies to documents and any other types of data. Any digital data can be called "digital assets", for example, a folder on a computer desktop, since the data composing this asset are stored on electronic media, on digital devices, including computers, mobile devices, media players, etc.

And each cryptocurrency can be marked as a digital asset. However, not every digital asset is a digital currency. An excellent example of this is XRP, which many specialists classify erroneously as cryptocurrency. This is a digital resource stored in a distributed register, and it does not work like a digital currency.

\footnotetext{
2 Fiat money (from Latin Fiat - the decree, "So mote it be") is money, the nominal value of which is established and guaranteed by the state, regardless of the value of the material from which the money is made, or located in a bank's depository (unsecured money).
} 
XRP in its case can only be used in the Ripple Consensus Ledger $^{3}$. Even in this case, the use of transactions in this register is not obligatory. The value of a digital resource often depends on the organization which they are connected with. Higher demand for such an asset often increases its value. However, the control of access and portability of these assets is supported by individual companies.

The majority of cryptocurrencies are known for their decentralized aspect, the security, contained in the very essence of the underlying mathematical algorithm in it. At the same time, cryptocurrency is characterized by management of the exchange discreteness (manipulation), which may not be typical for any other digital asset. Moreover, most cryptocurrencies have an offer limit, while digital assets can in theory be created indefinitely, if necessary. Obviously, these two types of values are very different from each other, which should always be considered.

\section{Cryptocurrency is a Law of Obligations}

The position that such a cryptocurrency as bitcoin is a mandatory claim right arising on the basis of an agreement between the participants of the corresponding settlement system was expressed by the Doctor of Law, Professor L. Novoselova. In support of her opinion, Professor L. Novoselova classifies bitcoin as non-cash money, insofar as bitcoin fulfils the function of money, its transfer for the purpose of paying for goods, works and services should be regarded as a final payment terminating the monetary obligation by execution ${ }^{9}$ [Novoselova 2017].

According to the legal construction of the law of obligations, a relative legal relationship is such in which there are specific participants bound to a certain conduct pursuing a property interest (as opposed to an absolute legal relationship in which an indefinite number of persons are opposed to the authorized person, for example, in property relations, operational management) i.e. in obligatory legal relations the obliged person always resists to the authorized person.

\footnotetext{
3 Ripple is a cryptocurrency platform for payment systems, focused on operations with the exchange of currencies without refunds. Developed by Company Ripple. The consensus register (ledger) is a special feature. The system was launched in 2012. The protocol supports "tokens" representing fiduciary money, cryptocurrency, exchange commodities or other objects. In its essence, Ripple is based on an open divided database, uses the process of agreement. It allows to make an exchange in a distributed process. The internal cryptocurrency of the Ripple network is called XRP.
}

The fact is that when you acquire a cryptocurrency, you, in fact, buy the right to use it, since the cryptocurrency does not have a real form - it does not physically exist, and all operations for buying and selling the cryptocurrency are records of transactions that are stored in multiple block chains (blockchain). That is, managing a cryptocurrency account, you manage as a matter of fact records and keys, which are stored in a wallet. In itself, joining in the platform and opening a digital wallet does not create the obligations of participants in such a system to acquire a cryptocurrency, i.e. the wallet can remain empty. After acquiring cryptocurrency by the participants, the participant does not have the obligations and the rights of claims to other participants of the system. At the same time, the participant treats as their own the cryptocurrency accountable in the crypto purse, and the publicity and the transparency of the data contained in the distributed registry Blockchain ensures the relevance (fixity) of the given property to the given participant in such a format that does not allow violation by all other participants.

Such a construction of relations reminds something of the principle of publicity in property law existing in German law, which is realized either in the form of a record in the land register (Grundbuch) (since only land plots are related to real estate here), or in the form provided for in $\$$ 929 BGB for the alienation of movable things "property contract" (Einigung). This latter is based on the "principle of abstraction" (Abstraktionsprinzip), or on the "principle of division" (Trennungsgrundsatz) of two transactions the obligatory (Verpflichtungsgeschaft), which generates the rights and obligations of its parties, and real, which is essentially the fulfillment of the transaction obligation (i.e. a kind of managerial transactions - Verfugungsgeschafte). By virtue of the "principle of abstractness", the person who obtained the movable thing by the "property contract" becomes its owner regardless of the validity of the transaction obligation, and the actual possession of the movable item is presumed as the owner's possession (compare paragraph 2 of $\$ 854$ BGB) [Bando, Bryukhov, Valeeva 2016, p. 15].

I believe that the cryptocurrency cannot be attributed to either obligatory (mandatory) or to proprietary rights, since it is not fully covered by those legal regimes that exist in property and obligatory law. The special regime with respect to certain objects of civil rights in fact is established not for the objects themselves, but for persons who commit legally significant actions with them. But different objects of civil rights in this capacity differ from 
each other precisely by their legal regime, as well as by their physical or economic properties, the peculiarities of such a regime being formed in the form of certain types of property (civil) rights. An example here is the allocation of non-cash funds and uncertified securities among other objects of civil rights and the establishment of special legal regulation.

Thus, in the absence of a special legal regime established by law in respect to cryptocurrency, there will be attempts to attribute it or to equate it with existing ones.

\section{Analysis}

After the analysis of the various sources it is possible to define the notion (concept) of cryptocurrency in the following way - it is a digital (virtual) currency, the creation and control of which are based on cryptographic methods (mathematical algorithms), in respect of full decentralization (absence of external or internal administrator in the network guaranteeing (confirming) the correctness of the operations of the system, including the lack of ability to influence the transaction participants in the system). The reliability of transactions is provided in the network by the Blockchain technology (replicated distributed database - technology of the distributed registry), algorithms of which allow to combine the transactions in "blocks" and add them into "chain" of the existing units to ensure the stability of the base of the chain of transactions blocks with the use of cryptography elements and consistent hashing. ${ }^{4}$ The continuity is ensured by the inclusion hash sum of the previous block into the current block, which does not alter the unit without changing the hashes in all subsequent blocks. As a guarantee, mathematical calculations are a certain value of the physical world.

Thus, the cryptocurrency is a completely new object of legal regulation, based on the fundamentally different approaches, which require different legal regulation at the national level and at the level of international legislation. For this reason it will be necessary to define the conceptual apparatus, to provide various legal regulations in respect of the function performed by the cryptocurrency (for example, the instability of the course of the cryptocurrency has negative consequences for the purposes of its use in the investment asset (for accumulation purposes), as a unit of measurement and income generation, as there are certain difficulties in the current cryptocurrencies in the

\footnotetext{
4 Hashing is a mathematical transformation of information. Hash algorithms are used to verify the integrity and authenticity of files.
}

form of obtaining interest income, as far as at present the yield of the cryptocurrency may come to the speculative growth or the drop in value, the creation of conditions for the competition of cryptocurrencies, legal grounds and conditions and the organization of activities by mining cryptocurrency, that is, the creation of rules protecting both private legal interests and public legal interests that ensure national security). In connection with this it will be necessary to identify a subject and provide liability in the event of a possible failure of the system, authorized or unauthorized modification of the program code, as well as the resulting consequences in the system and the procedure for eliminating them and restoring legal balance.

Cryptocurrency as an object of financial and legal regulation requires the definition of the nature of the cryptocurrency in the financial and legal sense, for the purpose of tax transactions, in connection with the use of cryptocurrency. It is necessary to consider that the approaches to the tax-legal regulation of any economic activity in various countries are not the same. The Internal Revenue Service (IRS) considers bitcoin as a property for the purposes of tax regulation, and not as a currency. Any transactions using bitcoins are taxed in accordance with the principles applied to property taxation. Thus, the owners of bitcoins must inform the IRS about all their transactions. The US tax residents who sell goods and services in exchange for cryptocurrency are obliged to include the cost of the obtained bitcoins in the annual tax return. It is calculated on the basis of a fair market price in the US dollars at the date of receipt (i.e. the exchange rate on that day). Cryptocurrency is considered as a capital asset in the hands of a taxpayer (similar to shares, bonds and other investment instruments), so this obliges to consider profits and losses when calculating the taxable base. The profit arises in the case when the sale price in the US dollars exceeds the adjusted purchase price. A loss arises when the sale price is lower than the adjusted purchase price. Miners who obtain bitcoins on their own equipment are also subject to taxation. They are also obliged to include the fair market value of the extracted cryptocurrency in their annual gross income [Aryanova 2017].

In 2015, the European Court of Justice (the highest court of the EU) ruled that operations in bitcoins are exempt from value-added tax (VAT) in accordance with the regulations governing circulation of currencies, banknotes and coins used as legal tender. Thus, according to the Court, bitcoin is a currency, not a property. Although no VAT is withheld when buying and selling bitcoins, other 
transactions may be taxed, for example, income tax or capital gains tax.

I believe that at present it is difficult to determine which tax policy in relation to the cryptocurrency will be chosen by the legislator. Everything depends on the way by which the cryptocurrency will be determined from the point of view of fiscal interest in the legislation, if as "goods", then VAT will be taken, if as "income" - then personal income tax and income tax. Further, it will be difficult to decide the question of how it is supposed to be paid - a certain tax only by ruble or by cryptocurrency, too. If we imagine such an opportunity, it will be necessary to create conditions for the creation and formation of crypto budget, following the example of the gold and foreign exchange reserve, which is formed from other assets, other than the national currency, both in the form and in the economic status and regime. Simultaneously with the definition of the order of taxation of cryptocurrency, the questions related to tax administration arise. Who and how will collect information, how will the accumulation and security of information be ensured, which will be considered a violation of the legislation on taxes and fees.

\section{Conclusion}

The above analysis confirms that much work needs to be done in a short time. The world does not stand still and at present there are polar situations where, on the one hand, rapidly developing information technologies are introduced into all spheres of society and human life, on the other hand, there is a lack of timely prepared legal mechanisms, the delayed implementation of which can have the opposite effect, when it is not the State that will manage the system, but the system will manage the State, the creation of a substance competing with the public order, through the existence of parallel systems, which can lead to strong competition and effective development, or vice versa to its suspension. Mankind has always tried to understand and to review the form and the role of money. We believe that the task of today's generation is to explain the need and necessity to transform money into a crypto virtual form. Accordingly, this cannot but affect the functioning of public finances. Because of this, it causes modernization of the legal regulation in the sphere of public finance. A special place in the modernization of legal regulation belongs to the rules of public financial law. It appears that a large group of rules is being formed in the system of public financial law, which are forming a complex of legal institutions that are transformed into the sub-sector of the public finance law - the issue law.

\section{Bibliography}

Aryanova T. (2017), The tax on the crypto-currency: Where and how much it is necessary to pay for operations in bitcoins.

Bando M.V.,Bryukhov N.G., Valeeva N. G. (2016), Private law. Overcoming the tests, "Statute" no. 15.

Harris L. (1990), Monetary theory, Progress, Moscow.

Hayek F. A. (1975), Private money, Institute of Economic Affairs, London.

Keynes J. M. (2016) General theory of employment, interest and money, Atlantic Publishers \& Dist, Delhi.

Luntz L. A. (2004), Money and monetary obligations in the civil law. -2nd ed., Statut, Moscow.

McConnell K. R., Bru S. L. (2003) Economics, Publishing House INFRA, Russia.

Novoselova L. (2017), About the legal nature of bitcoin, "Economy and Law" no. 15.

Ponsford M.P. (2015), A Comparative Analysis of Bitcoin and Other Decentralised Virtual Currencies: Legal Regulation in the People's Republic of China, Canada, and the United States, "HKJ Legal Studies" no. 9.

Prayogo G. (2018), Bitcoin, regulation and the importance of national legal reform, "Asian Journals of Law and Jurisprudence" no. 1(1).

Savelyev A. I. (2017), Crypto currency in the system of civil rights objects, "Law" no. 8.

\section{Author biography}

Imeda Tsindeliani - Prof., Head of Financial Law Department of the Russian State University of Justice, The Candidate of Legal Science, the Associate Professor. 